Vol. $7 \mid 20$ | International Journal of

№1 20 Medical and Surgical Sciences

\begin{tabular}{l|l} 
UA & UNIVERSIDAD \\
AUTONOMA \\
DE C C H I I L E
\end{tabular}

Carta al editor

EVOLUGIÓN DE LA SALUD, ENFERMEDAD Y

DISGAPAGIDAD DURANTE EL GAPITALISMO

\title{
Evolution of health, disease and disability during capitalism
}

\author{
Mónica Maribel Mata Miranda \\ Escuela Militar de Medicina, Centro Militar de Ciencias de la Salud, \\ Secretaría de la Defensa Nacional, Ciudad de México 11200, México. \\ Correo:mmcmaribel@gmail.com
}

Gustavo Jesús VÁzQuez ZaPiÉN

Escuela Militar de Medicina, Centro Militar de Ciencias de la Salud, Secretaría de la Defensa Nacional, Ciudad de México 11200, México.

Correo:gus1202@hotmail.com

Receipt: $30 / 07 / 2020$

Acceptance: $04 / 08 / 2020$

A lo largo del tiempo, el entendimiento del proceso salud-enfermedad ha evolucionado junto con los diversos ambientes y condiciones en los que se ha sumergido la sociedad, siendo diferentes las formas de atención, tratamiento y prevención. De igual manera, la estructura social y económica ha propiciado desigualdades en la atención médica, generando subclases sociales respecto al acceso a la atención de salud y a las capacidades físicas y funcionales. El presente escrito, introduce brevemente a las subclases sociales en la salud-enfermedad que han emergido a partir de la estructura económicosocial del capitalismo.

En las culturas premodernas, la enfermedad era considerada como algo mágico y solían atribuirla a la presencia de espíritus malignos, existiendo sanadores que utilizaban diferentes remedios físicos y mágicos, siendo considerada la salud como un asunto privado y no como una preocupación pública, por lo que no había ninguna autoridad que se preocupara de la salud. Sin embargo, con el surgimiento de la industrialización cambió drásticamente esta situación, retomándose un gran interés en la salud de la población y en el bienestar de los miembros que la conforman, emergiendo estudios demográficos que consideraban datos como tasas de natalidad, mortalidad, número de hijos, índices de suicidio, esperanza de vida, dietas, enfermedades habituales, causas de defunción, entre otras, asumiendo el Estado la responsabilidad de mejorar los sistemas de salubridad como el abastecimiento de agua, pavimentación de caminos y atención a la vivienda (Álvarez-Alva \& Kuri-Morales, 2018).

Sin embargo, lo más destacado de la industrialización en el ámbito de la salud-enfermedad fue la implementación de un modelo biomédico, el cual tenía como característica principal la aplicación de la ciencia al diagnóstico y tratamiento médico, es decir, la atención médica fue tomada en manos de 
expertos. No obstante, este modelo biomédico considerado como científico, con el paso del tiempo fue desacreditado y señalado por algunos autores como sobrevalorado, ya que los medicamentos proporcionados en ese momento no reducían en forma significativa las tasas de mortalidad, motivo por el cual la población retomó nuevamente la medicina alternativa, como la homeopatía y la acupuntura, siendo apróximadamente hasta los años treinta cuando los antibióticos y las vacunas tomaron gran fuerza por su eficacia.

Por otro lado, la industrialización trajo consigo nuevas tecnologías, las que según la visión de algunos sociólogos alejaron al cuerpo humano de lo natural y de su ritmo biológico, siendo invadido por tecnologías que van desde máquinas hasta dietas. Estas tecnologías que fueron denominadas por Foucault (1990) cómo tecnologías sociales que afectan al cuerpo, entendiéndose por tecnología social a la intervención regular sobre el funcionamiento humano, por ejemplo, la dieta, cirugías estéticas, ultrasonidos, comida refrigerada, entre otros. Esto motivó al surgimiento de nuevas enfermedades sin precedentes, como la obesidad, que acarrea una serie de problemas y padecimientos crónico degenerativos y que, a la fecha, es considerada como el mayor de los problemas de salud pública a nivel mundial. De igual manera, la globalización exteriorizada por la industrialización provocó el surgimiento de padecimientos dismórficos, buscando la integración a la sociedad mediante patrones de belleza, surgiendo la anorexia y la bulimia, enfermedades que en la actualidad son consideradas como un gran problema de salud pública entre la sociedad joven a nivel global (Giddens, 2014).

De igual manera, la adaptación del cuerpo humano a la industrialización desarrolló una serie de padecimientos psicológico-psiquiátricos, cómo estrés, depresión, insomnio, ansiedad, fatiga, déficit atencional infantil, entre otros, provocando el uso indiscriminado de fármacos, en su mayoría antidepresivos; a la fecha, la Organización Mundial de la Salud sostiene que la depresión es la enfermedad más incapacitante del mundo, pronosticando que para este año sería la segunda mayor causa global de enfermedad.

Asimismo, es importante mencionar que la estructura social que caracterizó al capitalismo impactó en el sistema de salud. Browne \& Bottrill (1999) entre otros investigadores sociales, revelaron las desigualdades sanitarias basadas en las clases sociales. De la misma forma, estudios realizados en otros países industrializados han confirmado la existencia de un gradiente de clase en relación con la salud, declarando que la desigualdad sanitaria relativa entre los miembros más ricos y los más pobres de la sociedad está aumentando. Sin embargo, pese a un número creciente de investigaciones que pretende poner de manifiesto el vínculo existente entre la desigualdad sanitaria y la clase social, no se ha logrado localizar realmente el mecanismo que conecta ambas cosas. Al respecto, algunos dirigentes políticos como Margaret Thatcher, justificaron esta desigualdad en las diferentes costumbres que practican los estratos sociales, manifestando que la clase baja fuma, consume mayor cantidad de alcohol, siguen una mala dieta, contribuyendo a la aparición de una mayor cantidad de enfermedades crónico degenerativas, lo cual también fue avalado por otros estudiosos de la época, motivo por el cual, en la actualidad se le ha dado mucha relevancia a la medicina preventiva para la búsqueda de mejorar las condiciones de salud en la totalidad de la estructura que conforma la sociedad (Giddens, 2014).

Siguiendo estos patrones de estudio en la sociedad, el modelo social de discapacidad ha separado a la sociedad en dos estratos: los capaces y los incapaces. Hunt afirmaba que la misma sociedad tiende a rechazar a las personas con capacidades diferentes, por lo que estableció una clara diferencia entre deficiencia y discapacidad, definiendo deficiencia como la carencia de un miembro o bien un órgano defectuoso; y por discapacidad como la restricción de actividades causada por una organización social contemporánea, es decir, la exclusión de éstas en la participación en actividades sociales, lo cual acarreó que muchas personas discapacitadas fueran incapaces de mantener sus empleos, por lo que se 
convirtieron en un problema social para el estado capitalista. Aunque mucho se ha avanzado en este ramo, aún existen países en los cuales no se consideran los derechos de las personas con capacidades diferentes y son excluidos de la sociedad.

Finalmente, otro de los temas más polémicos respecto a la atención de la salud en la industrialización, fue la fecundación in vitro más transferencia de embriones (FIV+TE), con lo cual se logró implantar en el vientre materno embriones que no portaran genes que podrían causar alguna enfermedad, además de la posibilidad de decidir antes del nacimiento características físicas como color de piel y de ojos, tipo de cabello, peso, estatura, entre otros. Igualmente podría existir la factibilidad de la reprogramación genética, con lo que algunos sociólogos han apuntado que este hecho podría causar la aparición de una subclase biológica y, aquellos que no posean los medios para acceder a la ingeniería genética, podrían estar sujetos a discriminación y vulnerabilidad (Mata-Miranda \& Vázquez-Zapién, 2018).

Con la globalización que se vive en un mundo capitalista, nuevas enfermedades y tratamiento médicos han surgido y con ello nuevos grupos sociales, como grupos de adolescentes que buscan pertenecer a un grupo social cumpliendo con un patrón de belleza mal encausado, personas que buscan la juventud y salud prolongada a través de tratamientos de medicina regenerativa, entre otros. Asimismo, se han evidenciado desigualdades sanitarias basadas en las clases sociales, y se ha proyectado la aparición de una subclase biológica conformada por superhombres con selección específica de genes y rasgos físicos previos a la concepción. ¿Será que en un futuro la estructura social biológica dividirá a la raza humana como superhumanos y humanos concebidos naturalmente?, ¿podrá ser que los superhumanos sean los que ocupen a futuro la punta de la pirámide social? o simplemente, ¿mejorarán las condiciones de vida y salud para la población?

\section{Referencias}

Álvarez-Alva R., Kuri-Morales P.A. Salud pública y medicina preventiva. $5^{\text {a }}$ ed. Manual Moderno, 2018.

Giddens A. Salud, enfermedad y discapacidad. Sociología. 6ª ed. Editorial Alianza, 2014.

Mata-Miranda M.M., VÁzQuez-Zapién G.J. La fecundación in vitro: Louise Brown, a cuatro décadas de su nacimiento. Revista de Sanidad Militar, 2018; 72(5-6): 363-365. 